\title{
Biocompatible metal-free organic phosphorescent nanoparticles for efficiently multidrug-resistant bacteria eradication
}

\author{
Shan Wang ${ }^{1 \dagger}$, Miao Xu ${ }^{1 \dagger}$, Kaiwei Huang ${ }^{1}$, Jiahuan $\mathrm{Zhi}^{1}$, Chen Sun ${ }^{1}$, Kai Wang ${ }^{1}$, Qian Zhou ${ }^{1}$, \\ Lingling Gao ${ }^{1}$, Qingyan $\mathrm{Jia}^{2}$, Huifang Shi ${ }^{{ }^{*}}$, Zhongfu $\mathrm{An}^{{ }^{1 *}}$, Peng $\mathrm{Li}^{1,2^{*}}$ and Wei Huang ${ }^{1,2}$
}

\begin{abstract}
Organic phosphorescence materials with longlived triplet excitons that can highly generate active singlet oxygen $\left({ }^{1} \mathrm{O}_{2}\right)$ through the energy transfer with the molecular oxygen under photoexcitation, serve as highly efficient antibacterial agent. Herein, we report bright red-emissive organic phosphorescent nanoparticles (PNPs) based on a metal-free organic phosphor encapsulated with biocompatible block copolymers. The obtained PNPs with an ultra-small particle size of around $5 \mathrm{~nm}$ and a long emission lifetime of up to $167 \mu \mathrm{s}$ showed effective ${ }^{1} \mathrm{O}_{2}$ generation ability under visible light $(410 \mathrm{~nm})$ excitation in aqueous media, which can efficiently eradicate multi-drug resistant bacteria both in vitro and in vivo. This is the first demonstration of metal-free organic PNPs for photodynamic antimicrobial therapy, expanding the application scope of metal-free organic room temperature phosphorescent materials.
\end{abstract}

Keywords: organic phosphorescence, singlet oxygen, antimicrobial, photodynamic therapy, multidrug-resistant bacterium

\section{INTRODUCTION}

Organic phosphorescence materials, owing to their long phosphorescence lifetime, tunable emission color, excellent stabilities and high quantum efficiency, have attracted great attention in optoelectronic fields such as organic light-emitting diodes (OLEDs) [1], bioelectronic fileds such as bio-imaging [2,3] and photodynamic cancer therapy [4], as well as photonics fields such as chemical sensors [5-8], anti-counterfeiting [9,10], and so on $[11,12]$. In previous years, organic phosphorescent ma- terials are largely limited to organometallic luminogens, such as $\mathrm{Pt}(\mathrm{II})$-, $\mathrm{Ru}(\mathrm{III})$-, $\mathrm{Ir}$ (III)-complexes, because the efficient spin-orbit coupling (SOC) induced by the heavymetal effect can promote phosphorescence emission $[13,14]$. However, recent attention has been transferred to metal-free organic phosphorescent materials on account of the drawbacks of the noble metals, such as high cost, high toxicity and scarce resource $[15,16]$. Different from organometallic luminogens, metal-free organic compounds are easier to synthesize, more stable and modifiable in molecular structures. Therefore, great efforts have been devoted to developing purely organic phosphorescence through various feasible strategies in recent years, including H-aggregation [17-24], crystal engineering [25-29], host-guest doping [30-33], polymerization [34-37] and so on [38-41]. Since previously reported metal-free organic room temperature phosphorescent materials are almost bulk crystals or powders, it is still a formidable challenge to develop the application of such materials in the bio-medical fields $[2,3]$.

In recent years, the emerging antibiotic-resistant bacteria have posed a serious threat to public health $[42,43]$. From 2005 to 2016, the incidence of hospital-onset and community-onset methicillin-resistant Staphylococcus aureus (MRSA) bloodstream infection has reached 74\% and $40 \%$, respectively. To crack this antibiotic-resistance crisis, various novel antimicrobials were proposed recently, including host defense peptides [44,45], immunomodulators [46], bacteriophages [47], silver nanoagents [48], etc. However, inherent drawbacks like

\footnotetext{
${ }^{1}$ Key Laboratory of Flexible Electronics (KLOFE) \& Institute of Advanced Materials (IAM), Nanjing Tech University (NanjingTech), Nanjing 211816, China

${ }^{2}$ Xi'an Institute of Flexible Electronics (IFE) \& Xi'an Institute of Biomedical Materials Engineering (IBME), Northwestern Polytechnical University (NPU), Xi'an 710072, China

$\dagger$ These authors contributed equally to this work.

* Corresponding authors (emails: iamhfshi@njtech.edu.cn (Shi H); iamzfan@njtech.edu.cn (An Z); iampli@nwpu.edu.cn (Li P))
} 
sophistication, high cost, and unpredictable threats to human health (e.g., cellular toxicity, skin staining, allergic reactions) impeded their biomedical applications [49-52]. Therefore, facilely prepared non-toxic antimicrobial agents with potent biocidal efficacy towards multidrugresistant bacteria are in urgent demand.

As we all know, reactive oxygen species (ROS) are commonly used as antibacterial agents because of their broad-spectrum sterilization ability [53-55]. Actually, the electrons of organic phosphorescence materials are excited from the ground state $\left(\mathrm{S}_{0}\right)$ to their first singlet excited state $\left(\mathrm{S}_{1}\right)$ under the photoexcitation, and then singlet excitons undergo a spin conversion and transfer into the triplet state $\left(T_{1}\right)$. Subsequently, energy transfer between $T_{1}$ state and the ground state (triplet state) of molecular oxygen in the air occurs, resulting in the generation of singlet oxygen $\left({ }^{1} \mathrm{O}_{2}\right)$ via the process of triplet-triplet annihilation (TTA) [5]. As one type of the ROS, the ${ }^{1} \mathrm{O}_{2}$ can not only increase the permeability to the bacterial membrane, causing substances outflow and loss of bacterial activity, but also directly damage the nucleotides or DNA repair enzymes to further kill bacteria $[56,57]$. Therefore, organic phosphorescence materials could be considered as novel efficient antimicrobial agents.

Here, we report a class of water-soluble metal-free phosphorescent nanoparticles (PNPs) that could effectively eliminate clinically significant "superbug" MRSA multidrug-resistant bacteria both in vitro and in vivo for the first time. In this work, PNPs with an ultrasmall particle size of less than $5 \mathrm{~nm}$ were prepared by encapsulating metal-free organic phosphor, (4,7-dibromo-5, 6-di(9H-carbazol-9-yl)benzo[c] [1,2,5] thiadiazole, DBCzBT) with biocompatible amphiphilic copolymers by a top-down method [3]. The energy transfer between the triplet state of the PNPs and the molecular oxygen in the air (triplet state) could result in the production of ${ }^{1} \mathrm{O}_{2}$ that can efficiently kill microorganisms under visible light illumination (Fig. 1a). This study will provide a new platform for extending the application of pure organic room temperature phosphorescent materials in photodynamic therapy for infections.

\section{EXPERIMENTAL SECTION}

\section{Materials}

Unless otherwise noted, all reagents used in the experiments were purchased from commercial sources without further purification. The bright red organic phosphorescent molecule (DBCz-BT) was synthesized according to previous studies. Phosphate buffered saline (PBS) obtained from Sigma-Aldrich was autoclaved at $121^{\circ} \mathrm{C}$ for sterilization before use. The LIVE/DEAD BacLight Bacterial Viability kit and the LIVE/DEAD Viability kit for mammalian cells were purchased from Thermo Fisher Scientific (USA). Luria-Bertani (LB) agar was purchased from Oxoid (USA). Bacteria strains (E. coli ATCC25922 and MRSA ATCC BAA40) were obtained from American Type Culture Collection (ATCC, USA).

\section{Measurements}

Ultraviolet-visible (UV-Vis) absorption spectra were measured by Shimadzu UV-1750. Steady-state fluorescence/phosphorescence and excitation spectra were measured using HitachiF-4600. The lifetime spectrum was carried out on an Edinburgh FLSP920 fluorescence spectrophotometer equipped with microsecond flashlamp ( $\mu$ F900). An ultrasonic cell disruptor (SCIENTZ-II D, JY92-IIN) was used to prepare nanoparticles. Transmission electron microscopy (TEM) was obtained on a JEOL JEM-2100 transmission electron microscope. Scanning electron microscopy (SEM) images were obtained by a (JSM-7800F) scanning electron microscope.

\section{PNPs preparation}

The transparent F127 aqueous solution $\left(3 \mathrm{mg} \mathrm{mL}^{-1}\right)$ was firstly prepared by dissolving F127 in deionized water. Then DBCz-BT powder (3 mg) was added into F127 aqueous solution under sonication at room temperature for 10 min (SCIENTZ-II D with $30 \%$ output). After sonication, the resulting mixture was filtrated with a polyvinylidene fluoride (PVDF) membrane with $0.22 \mu \mathrm{m}$ millipore to obtain homogenous nanoparticles.

\section{In vitro antimicrobial assays}

Bacteria (E. coli and MRSA) were harvested at mid-log phase and collected by centrifugation. The cell pellets were resuspended in PBS to a final concentration of $1 \times 10^{5}-1 \times 10^{6}$ colony-forming units $(\mathrm{CFU}) \mathrm{mL}^{-1}$, and cultured with PNPs for $60 \mathrm{~min}$ in a 96-well plate. The photodynamic bactericidal activity of PNPs was then determined by being exposed to a light of $410 \mathrm{~nm}$ for desired time. In the experiment to explore the relationship of toxicity with incubated concentration $(0,0.2,0.4$ and $0.8 \mathrm{mg} \mathrm{mL}^{-1}$ ) in PBS, cells were irradiated for $8 \mathrm{~min}$ and cells without added PNPs were used as a control group. In the experiment to test toxicity of PNPs as a function of light doses in PBS, the concentration of PNPs was $0.8 \mathrm{mg} \mathrm{mL}^{-1}$ and the cells were irradiated for $0,2,5$ and $10 \mathrm{~min}$, and then put in the dark for $120 \mathrm{~min}$. 
Thereafter, the retrieved cells were 10 -fold diluted to a series of concentrations for agar plating, and then the plates were incubated for $12-18 \mathrm{~h}$ for CFU counting. Three independently prepared samples were used in this assay.

\section{In vitro cytotoxicity determination}

$\mathrm{C} 2 \mathrm{C} 12$ cells (the clonal myoblastic cell line, bought from ATCC) were grown in the Dulbecco's Modified Eagle Medium (DMEM, Invitrogen) with 10\% $(v / v)$ fetal bovine serum (FBS), $100 \mathrm{U} \mathrm{mL}^{-1}$ penicillin and $100 \mu \mathrm{gL}^{-1}$ streptomycin and incubated under a humidified atmosphere containing $5 \% \mathrm{CO}_{2}$ at $37^{\circ} \mathrm{C}$. Then the $\mathrm{C} 2 \mathrm{C} 12$ cells were equally seeded in each well of 96 -well plates with a density of around 5000 cells per well. The in vitro cytotoxicity of the PNPs against $\mathrm{C} 2 \mathrm{C} 12$ cells was tested using AlamarBlue assay. Specifically, C2C12 cells were incubated in the 96-well plates for $4 \mathrm{~h}$. PNPs were mixed with DMEM so as to let the final concentration be $0.8 \mathrm{mg} \mathrm{mL}^{-1}$ into the well. The cells were cultured for 5 days, and the medium was changed every day. The cell viability was determined by AlamarBlue and LIVE/DEAD assays at day 1,3 and 5 .

\section{Burn wound model}

The in vivo animal experiments were approved by Nanjing Servicebio Technology Co., Ltd. China and used under protocols approved by the laboratory animal center of Nanjing Tech University. Specific pathogen-free Sprague-Dawley immune-competent male rats (Harlan, Horst, The Netherlands), 7-9 weeks old (200-220 g weight), were obtained from Nanjing Medical University. The rats were individually raised in cages at a standardized temperature for two days, with Standard rat chow and water supplied ad libitum. Prior to the experiments, a partial thickness burn wound was made on the shaved dorsum of the anesthetized rats by pressing against the rat skin for $6 \mathrm{~s}$ with a $1.5 \mathrm{~cm}$ diameter brass cylinder heated in a water bath at $90^{\circ} \mathrm{C}$ for $2 \mathrm{~min}$. A $10 \mu \mathrm{L}$ aliquot of bacteria solution containing a known number of MRSA $\left(1 \times 10^{8} \mathrm{CFU} \mathrm{mL}^{-1}\right)$ and PNPs $\left(0.8 \mathrm{mg} \mathrm{mL}^{-1}\right)$ were applied topically to the burn wound and cells without added PNPs were used as a control group. 10 min later, the rats were exposed to a light of $410 \mathrm{~nm}$ for $10 \mathrm{~min}$. After 1 and 3 days, skin tissue samples from the wound sites were collected for biochemical analysis.

\section{Bacteria load in skin}

The skin $(0.2 \mathrm{~g})$ was removed aseptically from the rat and homogenized in $2 \mathrm{~mL}$ of PBS $\left(0.1 \mathrm{~mol} \mathrm{~L}^{-1}, \mathrm{pH}\right.$ 7.2). The tissue homogenates were serially diluted. Bacteria load was determined by plating the dilution on nutrient agar plates and enumerated in terms of $\mathrm{CFU} \mathrm{mL}{ }^{-1}$. After the bacteria on the skin were freeze-dried, SEM was used to observe the bacteria on the skin surface.

\section{Histologic analysis}

On day 3 , specimens from all wound sites were harvested, followed by fixing in a $10 \%$ buffered formalin solution, and embedded in paraffin, which were used for hematoxylin and eosin (H\&E) staining and Masson's trichrome staining.

\section{RESULTS}

The metal-free organic phosphor DBCz-BT was synthesized according to our previous studies [58], which showed red emissive phosphorescence due to both intense intramolecular and intermolecular interactions caused by heavy halogen atoms (Fig. S1 (Supplementary information)). $\mathrm{DBCz}-\mathrm{BT}$ powders were encapsulated with a triblock copolymer, pluronic F127 (PEG- $b$-PPG- $b$-PEG) (Scheme S1). The amphiphilic structure of F127 holds the promise for the formation of aggregation in an aqueous solution with good biocompatibility (Fig. S2). The welldispersed PNPs possess the ultrasmall size of less than $5 \mathrm{~nm}$ observed by TEM (Fig. 1b), which will serve as a potential nanoprobe in the bio-application. Moreover, photophysical properties of PNPs in deionized water were fully studied. As shown in Fig. 1c, the excitation spectrum of PNPs reaches $520 \mathrm{~nm}$, which makes the visible-light excitation possible. Compared with ultraviolet light, visible light shows less phototoxicity. The photoluminescence (PL) spectrum of PNPs showed an intense red emission at $600 \mathrm{~nm}$, with emission lifetime as long as $167.29 \mu$ s under $410 \mathrm{~nm}$ excitation (Fig. 1d), demonstrating its phosphorescent nature. Surprisingly, the obtained water-soluble PNPs after encapsulation showed similar phosphorescence property as crystalline $\mathrm{DBCz}$ BT, which could be explained by the strong halogen bonding within aggregated nanoparticles (Fig. S1). As previously reported, this long lifetime of $\mathrm{T}_{1}$ state ensured the required bimolecular collision with $\mathrm{O}_{2}$ for easily occurring energy transfer [59].

In order to verify the potential bactericidal capacity of PNPs, their ${ }^{1} \mathrm{O}_{2}$ generation capability was determined. The chemical agent, 2,2'-(anthracene-9,10-diylbis(methylene)) dimalonic acid (ADMA) (Scheme S2), was used as a tracker to monitor the production of ${ }^{1} \mathrm{O}_{2}$ [60]. The mixed solution containing PNPs water solution $\left(0.8 \mathrm{mg} \mathrm{mL}^{-1}\right)$ and ADMA $\left(50 \mu \mathrm{gL}^{-1}\right)$ in a cuvette was 


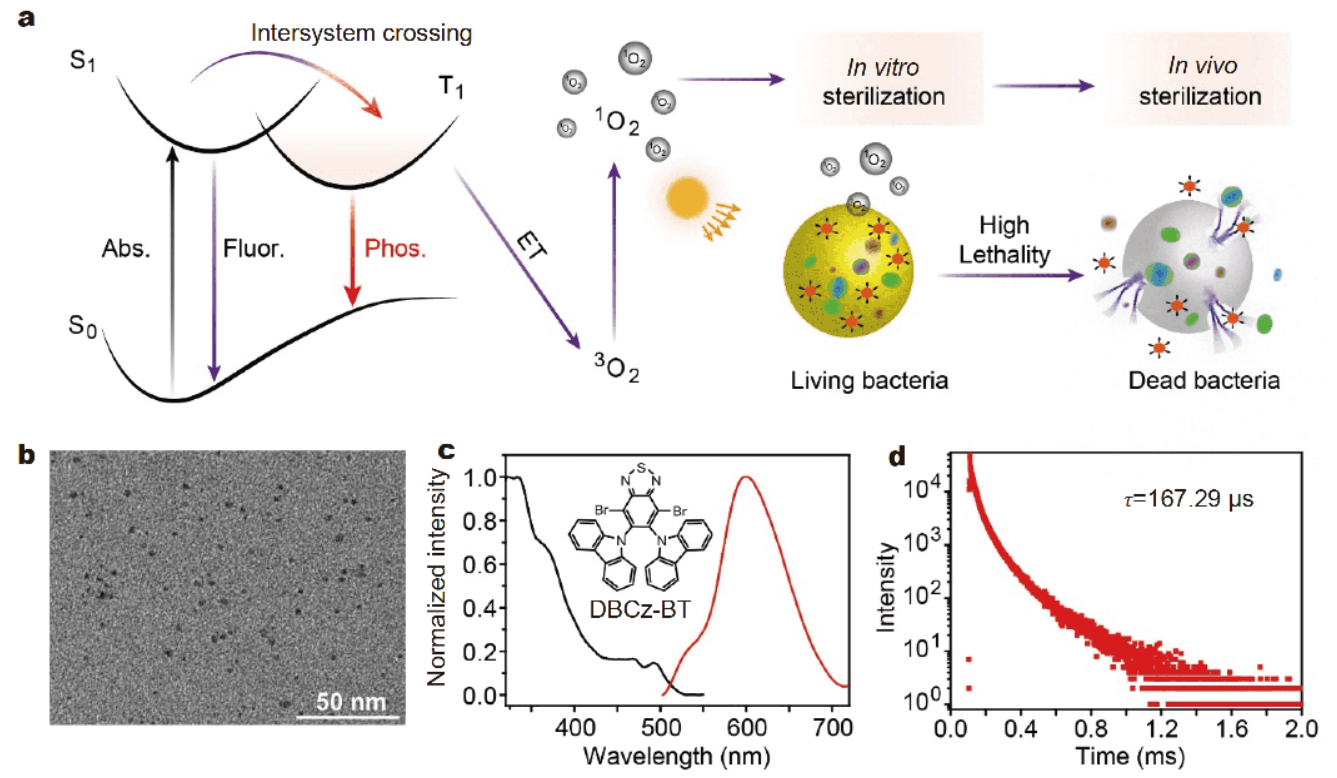

Figure 1 (a) Mechanism illustration of photodynamic antimicrobial process of PNPs. (b) TEM image of PNPs. (c) Normalized excitation (black line) and photoluminescence (red line) spectra of PNPs in deionized water. Inset: molecular structure of DBCz-BT. (d) Lifetime decay profile of an emission band at $600 \mathrm{~nm}$ of PNPs.

excited at $410 \mathrm{~nm}$. The photodegradation of ADMA was presented through absorption spectral quenching under the oxidation of ${ }^{1} \mathrm{O}_{2}$. As shown in the Fig. 2a, the characteristic absorbance at $260 \mathrm{~nm}$ of ADMA decreased faster within $10 \mathrm{~min}$ excitation than traditional photosensitizer-zinc(II) phthalocyanine, whose absorbance reduced within $40 \mathrm{~min}$ of illumination [60]. And in the inset of Fig. 2a, the absorbance at $260 \mathrm{~nm}$ reduced exponentially within 2 min excitation, which revealed an extremely fast generation rate of ${ }^{1} \mathrm{O}_{2}$, paving a way for the photodynamic antimicrobial.

Furthermore, the in vitro antimicrobial activity of PNPs was evaluated against two pathogenic microbes (Gramnegative bacterium: E. coli; Gram-positive bacterium: MRSA). As shown in Fig. 2b, MRSA and E. coil $\left(1 \times 10^{5}-\right.$ $1 \times 10^{6}$ CFUs) were incubated with different concentrations of PNPs ranging from 0 to $0.8 \mathrm{mg} \mathrm{mL}^{-1}$ for $1 \mathrm{~h}$ to make PNPs in full contact with bacteria and irradiated under $410 \mathrm{~nm}$ for $5 \mathrm{~min}$, then treated in the dark for $2 \mathrm{~h}$. As expected, the CFUs of E. coli and MRSA significantly decreased with the ascending of the concentration of the PNPs under light exposure. Almost all bacteria were killed when $c$ [PNPs $]=0.8 \mathrm{mg} \mathrm{mL}^{-1}$, and thus this concentration of PNPs was chosen for later studies. From Fig. $2 \mathrm{c}$ and Fig. S3a, there was little difference between the CFU of experimental group and control group in $0 \mathrm{~min}$ of irradiation for the two bacteria (E. coli and MRSA).
Meanwhile, no obvious phototoxicity was found, which can be identified by the nearly constant CFUs of the two bacteria (E. coli and MRSA) in blank control group under different irradiation times. And as the illumination time increases, the number of dead bacteria increases. The bactericidal rate of $E$. coli reaches almost $100 \%$ in $10 \mathrm{~min}$ of irradiation, while MRSA in $5 \mathrm{~min}$. Notably, the images of CFUs also showed that no viable bacteria were found for E. coli and MRSA after they were treated with PNPs followed by excitation at $410 \mathrm{~nm}$ for $10 \mathrm{~min}$ (Fig. $2 \mathrm{~d}$ and Fig. S2b). Therefore, PNPs $\left(0.8 \mathrm{mg} \mathrm{mL}^{-1}\right)$ showed extremely potent antimicrobial efficacy against the two pathogens and the bacteriostatic rates reached nearly $100 \%$ by excitation at $410 \mathrm{~nm}$ for $10 \mathrm{~min}$.

Aside from good antimicrobial activity, biocompatibility is another criterion to evaluate the feasibility of biomaterials in burn wound infection. The cytotoxicity of PNPs towards mouse cells (C2C12 myoblast cell line) was evaluated with AlamarBlue and LIVE/DEAD cell viability assays. $\mathrm{C} 2 \mathrm{C} 12$ cells are derived from the mouse muscle and skin containing muscle tissue, which are precursor cells for the regeneration of muscle tissue after trauma [61]. So C2C12 myoblasts was chosen to evaluate the biocompatibility of the PNPs. The cells were inoculated on the tissue culture polystyrene (TCPS) plate with a density of around 5000 cells per well and incubated for $5 \mathrm{~h}$ to permit adherence of cells. Then, the PNPs were 

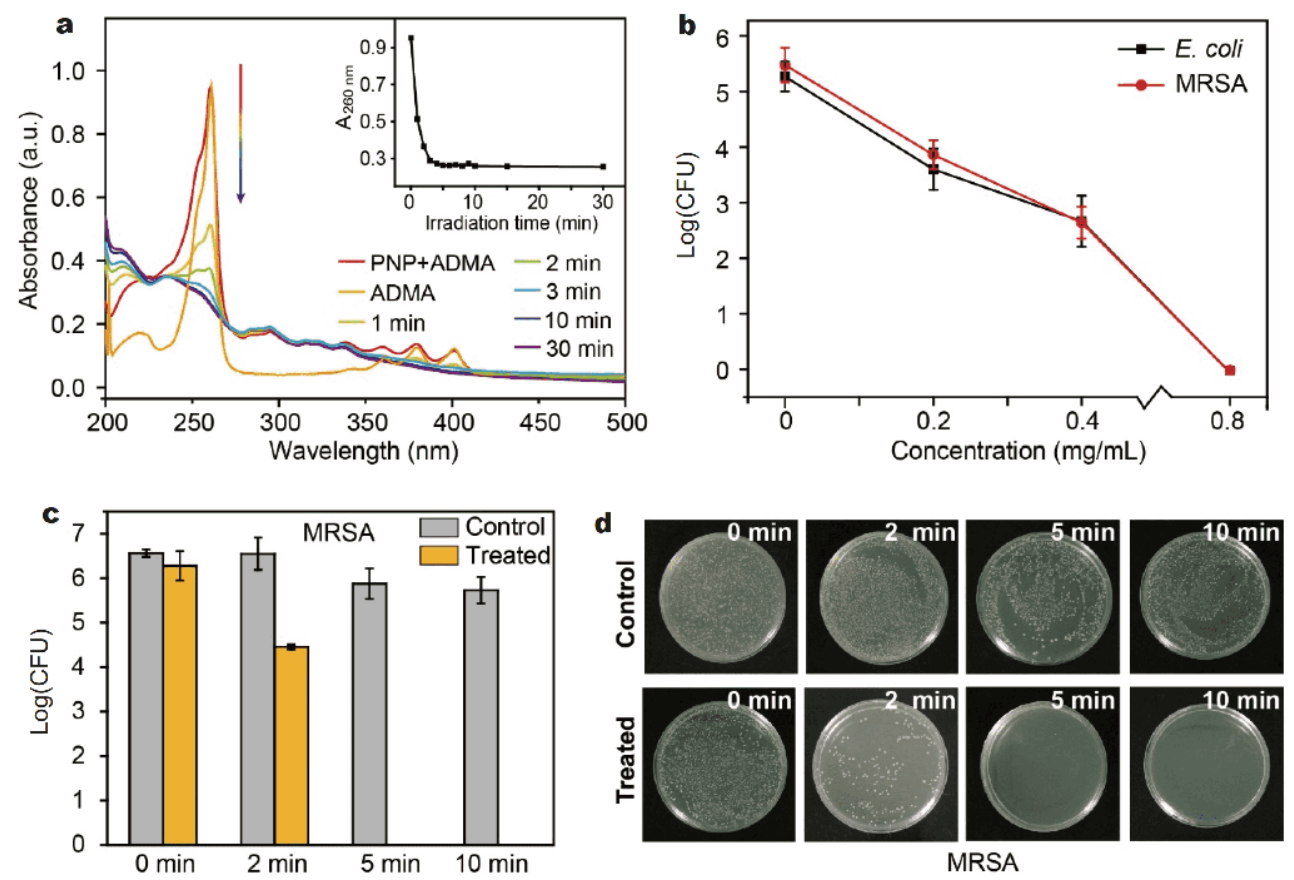

Figure 2 (a) Absorption spectra of ADMA alone, and ADMA with PNPs in PBS buffer under the $410 \mathrm{~nm}$ excitation ranging from 0 to 30 min. Inset: plot of function relation of absorbance at $260 \mathrm{~nm}$ and irradiation time. (b) The bactericidal efficacy of PNPs at different concentrations towards Gramnegative E. coli and Gram-positive MRSA in $\log (\mathrm{CFU})$ (irradiation for $5 \mathrm{~min}$ and incubation in dark for $2 \mathrm{~h}$ ). (c) The bactericidal efficacy of MRSA in $\log (\mathrm{CFU})$ of PNPs at $0.8 \mathrm{mg} \mathrm{mL}^{-1}$ with different irradiation times. (d) Images of MRSA growing on agar plates after treatment with and without PNPs for different irradiation times.

added as a treated group; TCPS was used as control. Fig. 3a shows that the cell viability still exceeds $95 \%$ in the high concentration of PNPs $\left(0.8 \mathrm{mg} \mathrm{mL}^{-1}\right)$ after incubation for 5 days. From Fig. S4, the fluorescence intensity of cells increased with the incubation time, suggesting that the $\mathrm{C} 2 \mathrm{C} 12$ proliferated with the existence of the PNPs. Meanwhile, almost all the cells were stained green after cultivation for 5 days, indicating that they were still alive (Fig. 3d, e). Thus, all these results demonstrated that the PNPs with low cytotoxicity and good biocompatibility can be regarded as the photodynamic antibacterial agent for in vivo anti-infection applications.

The MRSA is one of the most common multi-drug resistant bacteria in clinical practice. The photodynamic antimicrobial therapeutic effects of PNPs against MRSA infections were further investigated in the rat MRSA skin burn infection model. Burn infection is a kind of devastating injury that can damage the skin's defense system [62]. Burn infection is one of the most serious complications; $22 \%$ deaths of burn patients are related to sepsis from burn wound infections [63]. As shown in Fig. 4a, the back skin of the mouse that received the burn wound infliction and MRSA was used to cause infection, and the treated group further accepted PNPs treatment while the control group did not. Then both groups were put under the visible light irradiation. From the SEM of the skin epidermis, most of the bacteria on the epidermis have been killed for PNPs-treated group after three days (Fig. 4b, c). The CFUs of MRSA in the skin homogenate at the wound were counted (Fig. $4 \mathrm{~d}$ ). The bacteria proliferation of PNPs-treated group was well controlled compared with the untreated group (control). Subsequently, histopathological examination was given to observe the wound healing of mouse skin. The anatomy of PNPs-treated mouse skin was compared with that of the untreated group (control). The control group showed largish detachment and breakage of epidermis along with inflammation (dotted portion) (Fig. 4e). However, there were intact dermis and epidermis in the skin tissue similar to the normal skin when treated with PNPs formulations (Fig. 4f). Therefore, the developed PNPs formulation can effectively induce the bacteria death and is considered nonirritant and safe for in vivo anti-infection applications.

\section{DISCUSSION}

Since the intrinsic drawback of organometallic phosphors, such as molecular instability, expensive and re- 

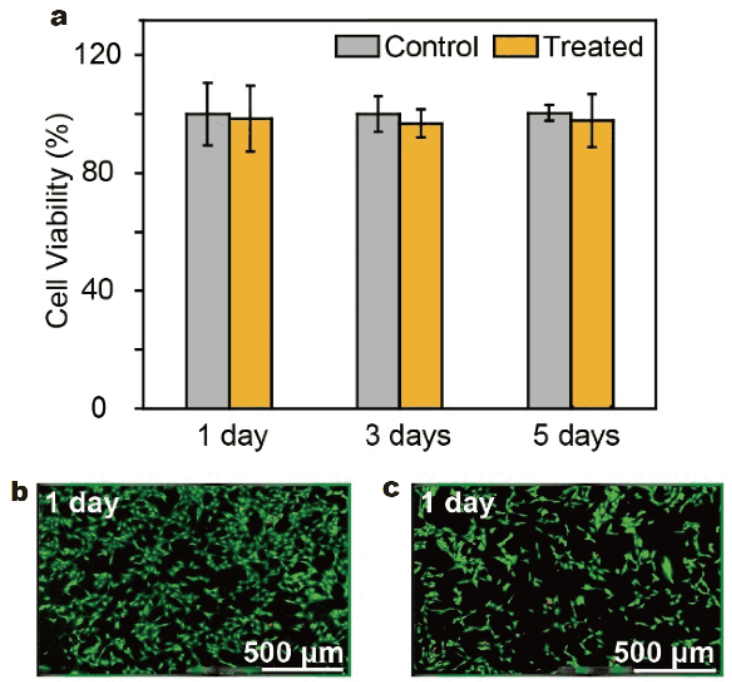

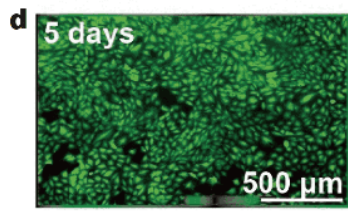

Control

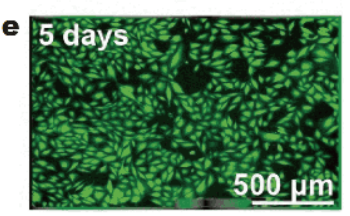

Treated
Figure 3 In vitro biocompatibility. (a) Percentage viability relative to TCPS control group. Each data point represents the mean \pm standard deviation for five separately prepared samples $(n=5)$. LIVE/DEAD fluorescent images of $\mathrm{C} 2 \mathrm{C} 12$ cells cultured in the presence of the control group ((b) and (d)) and hydrogel treated group ((c) and (e)) on 1 and 5 days (scale bar: $500 \mu \mathrm{m}$ ).

source-limited noble metals, metal-free organic luminogens with room temperature phosphorescence (RTP) are attractive alternatives in bioelectronics. However, most of the traditionally reported RTP materials are limited to bulk materials. The inherent defects of these bulk materials such as brittleness and bulkiness greatly limit their practical application in the bio-medical fields. Besides, the inherent drawbacks of antimicrobials reported previously (including host defense peptides, immunomodulators, bacteriophages, silver nanoagents) like sophistication, high cost, and unpredictable threats to human health (such as cellular toxicity, skin staining, allergic reactions) impeded their biomedical applications. Our work provides a new platform for preparing functional phosphorescence nanoprobes as non-toxic antimicrobial agents with potent biocidal efficacy towards multidrugresistant bacteria, expanding the application scope to biomedical fields. Meanwhile, there is great potential for the organic phosphorescence nanoparticles in the application of bioimaging $[2,64]$. There is strong background fluorescence interference in the practical bio-applications, giving the chance to use organic phosphorescence nanoparticles with long emission lifetime, time-resolved techniques to effectively eliminate the background fluorescence interference to improve the signal-to-noise ratio of imaging.

\section{CONCLUSIONS}

In summary, a type of water-soluble and biocompatible PNPs has been developed for treating microbial infections both in vitro and in vivo. Bright red phosphorescence achieved by strong halogen bonding can be observed in
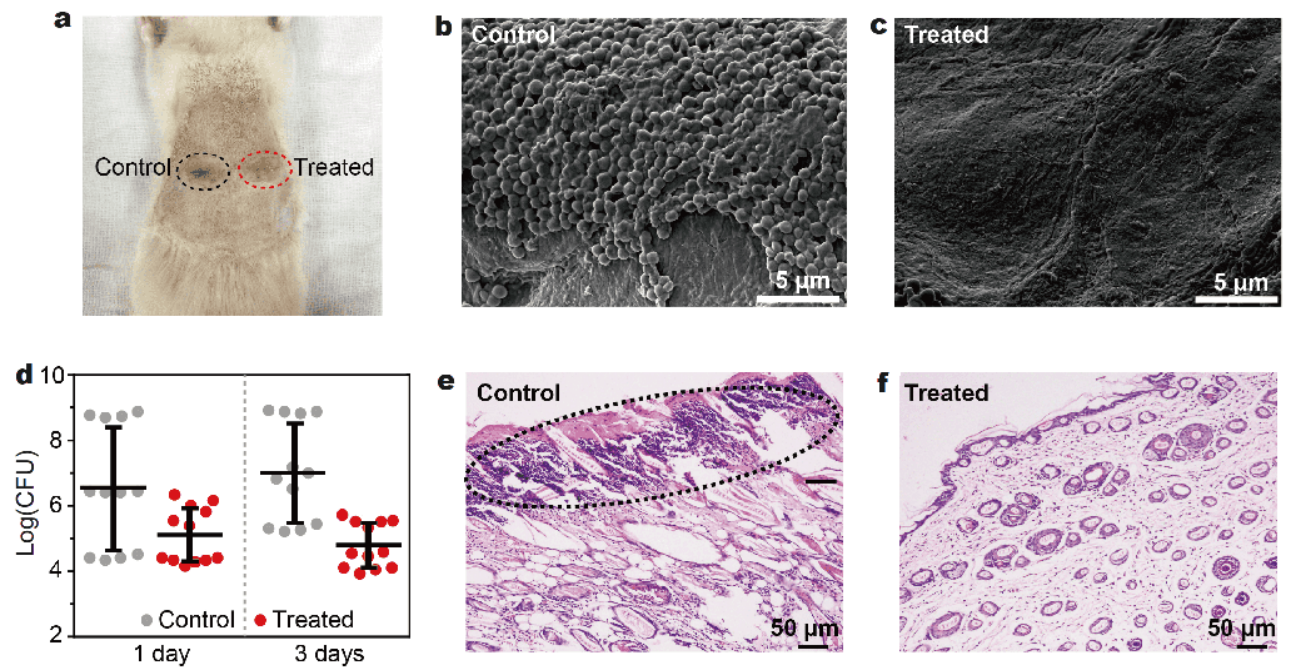

Figure 4 In vivo anti-infective activity. (a) Photographs of rat burn infective wound model. SEM observation of the skin removed on day 3 to control (b) and treated (c). (d) Number of viable MRSA recovered from the wound skin after 1, 3 days load in the burn wound infective model ( $n=4$, ${ }^{* *} p<0.001$ ). H\&E images of the tissue adjacent to control (e) and treated (f) on day 3 (scale bar: $5 \mu \mathrm{m}$ ). 
aqueous solution by the naked eye under visible light excitation, which is expected to be applied to bacterial detection through specific light emission. An efficient energy transfer between the PNPs and the ground state of oxygen allows the efficient generation of ${ }^{1} \mathrm{O}_{2}$, resulting in a potent antimicrobial activity and excellent therapeutic effects in vitro and in vivo. To the best of our knowledge, this is the first example of metal-free organic phosphorescence nanomaterials used in the field of photodynamic antimicrobial. Thus, the visible-light-excited PNPs may provide a new platform for preparing functional phosphorescence nanoprobes and expanding the application scope to biomedical fields.

Received 9 July 2019; accepted 22 September 2019; published online 7 November 2019

1 Kabe R, Notsuka N, Yoshida K, et al. Afterglow organic lightemitting diode. Adv Mater, 2016, 28: 655-660

2 Zhen X, Tao Y, An Z, et al. Ultralong phosphorescence of watersoluble organic nanoparticles for in vivo afterglow imaging. Adv Mater, 2017, 29: 1606665-1606671

3 Fateminia SMA, Mao Z, Xu S, et al. Organic nanocrystals with bright red persistent room-temperature phosphorescence for biological applications. Angew Chem Int Ed, 2017, 56: 12160-12164

4 Shi $\mathrm{H}, \mathrm{Ma} \mathrm{X}$, Zhao Q, et al. Ultrasmall phosphorescent polymer dots for ratiometric oxygen sensing and photodynamic cancer therapy. Adv Funct Mater, 2014, 24: 4823-4830

5 DeRosa CA, Seaman SA, Mathew AS, et al. Oxygen sensing difluoroboron $\beta$-diketonate polylactide materials with tunable dynamic ranges for wound imaging. ACS Sens, 2016, 1: 1366-1373

6 Lehner P, Staudinger C, Borisov SM, et al. Ultra-sensitive optical oxygen sensors for characterization of nearly anoxic systems. Nat Commun, 2015, 5: 4460-4466

7 Cheng Z, Shi $\mathrm{H}$, Ma $\mathrm{H}$, et al. Ultralong phosphorescence from organic ionic crystals under ambient conditions. Angew Chem Int Ed, 2018, 57: 678-682

$8 \mathrm{Wu} \mathrm{Q}$, Ma $\mathrm{H}$, Ling $\mathrm{K}$, et al. Reversible ultralong organic phosphorescence for visual and selective chloroform detection. ACS Appl Mater Interfaces, 2018, 10: 33730-33736

9 Yang Z, Mao Z, Zhang X, et al. Intermolecular electronic coupling of organic units for efficient persistent room-temperature phosphorescence. Angew Chem Int Ed, 2016, 55: 2181-2185

10 Wei J, Liang B, Duan R, et al. Induction of strong long-lived roomtemperature phosphorescence of $\mathrm{N}$-phenyl-2-naphthylamine molecules by confinement in a crystalline dibromobiphenyl matrix. Angew Chem Int Ed, 2016, 55: 15589-15593

$11 \mathrm{Yu} \mathrm{Z,} \mathrm{Wu} \mathrm{Y,} \mathrm{Xiao} \mathrm{L,} \mathrm{et} \mathrm{al.} \mathrm{Organic} \mathrm{phosphorescence} \mathrm{nanowire}$ lasers. J Am Chem Soc, 2017, 139: 6376-6381

12 Hirata S, Totani K, Yamashita $\mathrm{T}$, et al. Large reverse saturable absorption under weak continuous incoherent light. Nat Mater, 2014, 13: 938-946

13 Lo KKW, Louie MW, Zhang KY. Design of luminescent iridium (III) and rhenium(I) polypyridine complexes as in vitro and in vivo ion, molecular and biological probes. Coord Chem Rev, 2010, 254: 2603-2622

14 Schulte TR, Holstein JJ, Krause L, et al. Chiral-at-metal phos- phorescent square-planar $\mathrm{Pt}(\mathrm{II})$-complexes from an achiral organometallic ligand. J Am Chem Soc, 2017, 139: 6863-6866

15 Xia Z, Meijerink A. Ce ${ }^{3+}$-doped garnet phosphors: Composition modification, luminescence properties and applications. Chem Soc Rev, 2017, 46: 275-299

$16 \mathrm{Xu} \mathrm{H}$, Chen $\mathrm{R}$, Sun $\mathrm{Q}$, et al. Recent progress in metal-organic complexes for optoelectronic applications. Chem Soc Rev, 2014, 43: 3259-3302

17 An Z, Zheng C, Tao Y, et al. Stabilizing triplet excited states for ultralong organic phosphorescence. Nat Mater, 2015, 14: 685-690

18 Shi H, Song L, Ma H, et al. Highly efficient ultralong organic phosphorescence through intramolecular-space heavy-atom effect. J Phys Chem Lett, 2019, 10: 595-600

19 Cai S, Shi H, Li J, et al. Visible-light-excited ultralong organic phosphorescence by manipulating intermolecular interactions. Adv Mater, 2017, 29: 1701244-1701249

$20 \mathrm{Gu} \mathrm{L}$, Shi H, Gu M, et al. Dynamic ultralong organic phosphorescence by photoactivation. Angew Chem Int Ed, 2018, 57: 84258431

21 Cai S, Shi H, Zhang Z, et al. Hydrogen-bonded organic aromatic frameworks for ultralong phosphorescence by intralayer $\pi-\pi$ interactions. Angew Chem Int Ed, 2018, 57: 4005-4009

$22 \mathrm{Gu} \mathrm{L}$, Shi H, Bian L, et al. Colour-tunable ultra-long organic phosphorescence of a single-component molecular crystal. Nat Photonics, 2019, 13: 406-411

23 Gu L, Shi H, Miao C, et al. Prolonging the lifetime of ultralong organic phosphorescence through dihydrogen bonding. J Mater Chem C, 2018, 6: 226-233

24 Cai S, Shi H, Tian D, et al. Enhancing ultralong organic phosphorescence by effective $\pi$-type halogen bonding. Adv Funct Mater, 2018, 28: 1705045-1705051

25 Yuan WZ, Shen XY, Zhao H, et al. Crystallization-induced phosphorescence of pure organic luminogens at room temperature. J Phys Chem C, 2010, 114: 6090-6099

26 Bolton O, Lee K, Kim HJ, et al. Activating efficient phosphorescence from purely organic materials by crystal design. Nat Chem, 2011, 3: 205-210

27 Yang J, Zhen X, Wang B, et al. The influence of the molecular packing on the room temperature phosphorescence of purely organic luminogens. Nat Commun, 2018, 9: 840-849

28 Chen J, Yu T, Ubba E, et al. Achieving dual-emissive and timedependent evolutive organic afterglow by bridging molecules with weak intermolecular hydrogen bonding. Adv Opt Mater, 2019, 7: 1801593-1801599

29 Bian L, Shi H, Wang X, et al. Simultaneously enhancing efficiency and lifetime of ultralong organic phosphorescence materials by molecular self-assembly. J Am Chem Soc, 2018, 140: 10734-10739

30 Hirata S, Totani K, Zhang J, et al. Efficient persistent room temperature phosphorescence in organic amorphous materials under ambient conditions. Adv Funct Mater, 2013, 23: 3386-3397

31 Kwon MS, Lee D, Seo S, et al. Tailoring intermolecular interactions for efficient room-temperature phosphorescence from purely organic materials in amorphous polymer matrices. Angew Chem Int Ed, 2014, 53: 11177-11181

32 Louis $\mathrm{M}$, Thomas $\mathrm{H}$, Gmelch $\mathrm{M}$, et al. Blue-light-absorbing thin films showing ultralong room-temperature phosphorescence. Adv Mater, 2019, 31: 1807887-1807891

33 Hirata S, Vacha M. White afterglow room-temperature emission from an isolated single aromatic unit under ambient condition. Adv Opt Mater, 2017, 5: 1600996-1601006 
34 Ogoshi T, Tsuchida H, Kakuta $\mathrm{T}$, et al. Ultralong room-temperature phosphorescence from amorphous polymer poly(styrene sulfonic acid) in air in the dry solid state. Adv Funct Mater, 2018, 28: 1707369-1707375

35 Zhang G, Palmer GM, Dewhirst MW, et al. A dual-emissive-materials design concept enables tumour hypoxia imaging. Nat Mater, 2009, 8: 747-751

36 Chen H, Yao X, Ma X, et al. Amorphous, efficient, room-temperature phosphorescent metal-free polymers and their applications as encryption ink. Adv Opt Mater, 2016, 4: 1397-1401

$37 \mathrm{Ma} \mathrm{X}, \mathrm{Xu} \mathrm{C}$, Wang J, et al. Amorphous pure organic polymers for heavy-atom-free efficient room-temperature phosphorescence emission. Angew Chem, 2018, 130: 11020-11024

38 Koch M, Perumal K, Blacque O, et al. Metal-free triplet phosphors with high emission efficiency and high tunability. Angew Chem Int Ed, 2014, 53: 6378-6382

39 Yang J, Ren Z, Xie Z, et al. AIEgen with fluorescence-phosphorescence dual mechanoluminescence at room temperature. Angew Chem Int Ed, 2017, 56: 880-884

40 Wang XF, Xiao H, Chen PZ, et al. Pure organic room temperature phosphorescence from excited dimers in self-assembled nanoparticles under visible and near-infrared irradiation in water. J Am Chem Soc, 2019, 141: 5045-5050

41 Wang J, Gu X, Ma H, et al. A facile strategy for realizing room temperature phosphorescence and single molecule white light emission. Nat Commun, 2018, 9: 2963-2971

42 Tacconelli E, Carrara E, Savoldi A, et al. Discovery, research, and development of new antibiotics: The who priority list of antibioticresistant bacteria and tuberculosis. Lancet Infect Dis, 2018, 18: 318-327

43 Christou A, Agüera A, Bayona JM, et al. The potential implications of reclaimed wastewater reuse for irrigation on the agricultural environment: The knowns and unknowns of the fate of antibiotics and antibiotic resistant bacteria and resistance genes-A review. Water Res, 2017, 123: 448-467

44 Kumar P, Kizhakkedathu JN, Straus SK. Antimicrobial peptides: Diversity, mechanism of action and strategies to improve the activity and biocompatibility in vivo. Biomolecules, 2018, 8: 4

45 Zhang D, Qian Y, Zhang S, et al. Alpha-beta chimeric polypeptide molecular brushes display potent activity against superbugs-methicillin resistant staphylococcus aureus. Sci China Mater, 2019, 62: 604-610

46 Fumery M, Singh S, Dulai PS, et al. Natural history of adult ulcerative colitis in population-based cohorts: A systematic review. Clin Gastroenterol Hepatol, 2018, 16: 343-356

47 Miller-Ensminger T, Garretto A, Brenner J, et al. Bacteriophages of the urinary microbiome. J Bacteriol, 2018, 200: 365-373

48 Zheng K, Setyawati MI, Leong DT, et al. Antimicrobial silver nanomaterials. Coord Chem Rev, 2018, 357: 1-17

49 Lam SJ, O'Brien-Simpson NM, Pantarat N, et al. Combating multidrug-resistant gram-negative bacteria with structurally nanoengineered antimicrobial peptide polymers. Nat Microbiol, 2016, 1: 16162

50 Panáček A, Kvítek L, Smékalová M, et al. Bacterial resistance to silver nanoparticles and how to overcome it. Nat Nanotech, 2018, 13: $65-71$

51 Klose CSN, Artis D. Innate lymphoid cells as regulators of immunity, inflammation and tissue homeostasis. Nat Immunol, 2016, 17: 765-774

52 Lu LL, Suscovich TJ, Fortune SM, et al. Beyond binding: Antibody effector functions in infectious diseases. Nat Rev Immunol, 2018, 18: $46-61$

53 Li Y, Liu X, Tan L, et al. Rapid sterilization and accelerated wound healing using $\mathrm{Zn}^{2+}$ and graphene oxide modified $\mathrm{g}-\mathrm{C}_{3} \mathrm{~N}_{4}$ under dual light irradiation. Adv Funct Mater, 2018, 28: 18002991800310

54 Zhang X, Xia LY, Chen X, et al. Hydrogel-based phototherapy for fighting cancer and bacterial infection. Sci China Mater, 2017, 60: 487-503

55 Zhang M, Zhang C, Zhai X, et al. Antibacterial mechanism and activity of cerium oxide nanoparticles. Sci China Mater, 2019, 58: $1-13$

56 Yuan $\mathrm{H}$, Chong H, Wang B, et al. Chemical molecule-induced light-activated system for anticancer and antifungal activities. J Am Chem Soc, 2012, 134: 13184-13187

57 Liu K, Liu Y, Yao Y, et al. Supramolecular photosensitizers with enhanced antibacterial efficiency. Angew Chem Int Ed, 2013, 52: 8285-8289

58 Shi H, Zou L, Huang K, et al. A highly efficient red metal-free organic phosphor for time-resolved luminescence imaging and photodynamic therapy. ACS Appl Mater Interfaces, 2019, 11: $18103-18110$

59 Ogilby PR. Singlet oxygen: There is indeed something new under the sun. Chem Soc Rev, 2010, 39: 3181-3209

60 Ma X, Sreejith S, Zhao Y. Spacer intercalated disassembly and photodynamic activity of zinc phthalocyanine inside nanochannels of mesoporous silica nanoparticles. ACS Appl Mater Interfaces, 2013, 5: 12860-12868

61 Kawesa S, Vanstone J, Tsilfidis C. A differential response to newt regeneration extract by $\mathrm{C} 2 \mathrm{C} 12$ and primary mammalian muscle cells. Skeletal Muscle, 2015, 5: 19-34

62 Mofazzal Jahromi MA, Sahandi Zangabad P, Moosavi Basri SM, et al. Nanomedicine and advanced technologies for burns: Preventing infection and facilitating wound healing. Adv Drug Deliver Rev, 2018, 123: 33-64

63 Fitzwater J, Purdue GF, Hunt JL, et al. The risk factors and time course of sepsis and organ dysfunction after burn trauma. J Trauma-Injury Infection Critical Care, 2003, 54: 959-966

64 Miao Q, Xie C, Zhen X, et al. Molecular afterglow imaging with bright, biodegradable polymer nanoparticles. Nat Biotechnol, 2017, 35: $1102-1110$

Acknowledgements This work was supported by the National Key R\&D Program of China (2018YFC1105402 and 2017YFA0207202), the National Natural Science Foundation of China (21975120, 21875104, 51673095 and 21875189), the National Basic Research Program of China (973 Program, 2015CB932200), the Natural Science Fund for Distinguished Young Scholars of Jiangsu Province (BK20180037), the Natural Science Fund for Colleges and Universities of Jiangsu Province (17KJB430020), and the Key R\&D Program of Jiangsu Province (BE2017740).

Author contributions Shi H, An Z, Li P and Huang W conceived the experiments. Wang $\mathrm{S}$ and Xu M wrote the manuscript. Shi H, Zhou Q, Li P, An Z and Huang W revised the manuscript. Wang S, Xu M, Huang K, Sun C, Wang K, Zhi J, Zhou Q, Gao L and Jia Q were primarily responsible for the experiments. Huang $\mathrm{K}$ and Zhou $\mathrm{Q}$ conducted the TEM measurement and analysis. Sun C, Zhi J and Wang K supplemented the raw materials. Gao L and Jia $\mathrm{Q}$ performed the animal experiment. All authors contributed to the data analyses. 
Conflict of interest The authors declare that they have no conflict of interest.

Supplementary information online version of the paper.

Supporting data are available in the

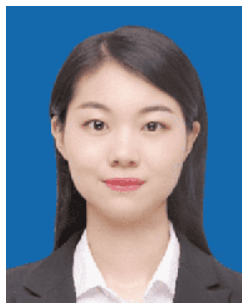

Shan Wang received her BSc from the Department of Chemical Engineering and Technology of Nanjing Tech University in 2016. And then she received her MSc under the supervision of Prof. Wei Huang and Prof. Zhongfu An in Nanjing Tech University. Her research focuses on the preparation of ultralong organic phosphorescent materials and phosphorescent nanomaterials for biological applications.

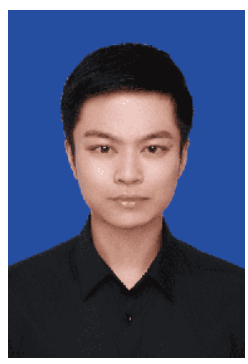

Miao Xu received his BSc from the School of Life Sciences of Tai Zhou University in 2016. And then he received his MSc under the supervision of Prof. Xiao Huang and Prof. Peng Li in Nanjing Tech University. His research focuses on the preparation of multi-functional antimicrobial materials for biological applications.

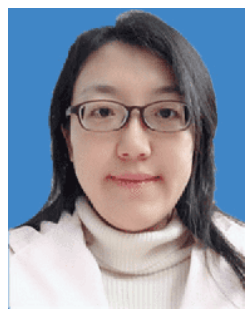

Huifang Shi received her BSc and BA from Qingdao University of Science \& Technology in China in 2008, PhD from Nanjing University of Posts and Telecommunications in 2013. Then she went to Nanyang Technological University in Singapore as a research fellow. She joined the Institute of Advanced Materials (IAM), Nanjing Tech University in 2015 as an Associate Professor. Her present research focuses on organic phosphorescent functional materials for sensing, bioimaging and cancer therapy.

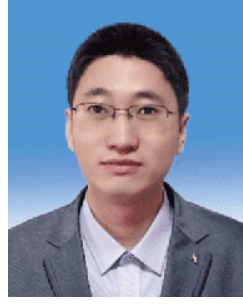

Zhongfu An received his $\mathrm{PhD}$ from Nanjing University of Posts and Telecommunications in 2014. After graduation, he went to National University of Singapore for a post-doctoral research in the Department of Chemistry. In 2015, he joined the IAM, Nanjing Tech University. He was promoted exceptionally as a full professor in 2016. His research interest focuses on organic electronics, including organic optoelectronic materials and devices; ultralong organic phosphorescent materials and applications.

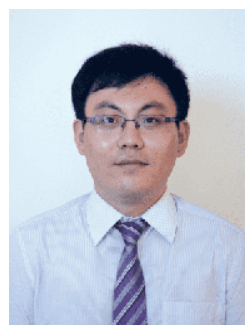

Peng Li is a professor at Northwestern Polytechnical University in China. He received his BE from Tianjin University in 2006 and $\mathrm{PhD}$ from Nanyang Technological University in 2013. In 2018, Prof. Li joined the Institute of Flexible Electronics (IFE) at Northwestern Polytechnical University. The primary goal of his research team is to develop innovative antibacterial materials and strategies for infection treatments.

\section{具有生物相容性的纯有机磷光纳米粒子有效杀灭 耐药细菌}

王姗 ${ }^{1 \dagger}$, 徐沝 ${ }^{1 \dagger}$, 黄凯薇 ${ }^{1}$, 支佳欢 ${ }^{1}$, 孙晨 ${ }^{1}$, 王楷 ${ }^{1}$, 周倩 ${ }^{1}$, 高玲玲 ${ }^{1}$, 贾庆岩 ${ }^{2}$, 史慧芳 ${ }^{1 *}$, 安众福 ${ }^{* *}$, 李鹏 ${ }^{1,2 *}$, 黄维 ${ }^{1,2}$

摘要 具有长寿命三线态激子的有机磷光材料在光激发下, 通过与 分子氧的能量传递可产生高活性的单线态氧 $\left({ }^{1} \mathrm{O}_{2}\right)$, 该单线态氧具 有抗菌能力. 然而, 传统的有机金属磷光材料的高毒性严重限制了 它们在生物医学领域的实际应用. 相较于金属有机材料, 不含金属 的纯有机磷光纳米粒子具有良好的水分散性和生物相容性, 可作 为抗菌材料被重点研究. 本文以无金属有机磷光粉 DBCz-BT $(4,7-$ 二溴-5,6-二(9H-咔唑-9-酰基)苯并 $[c][1,2,5]$ 噻二唑)为原料, 并利用 具有生物相容性的嵌段共聚物将其包裹, 成功制备了具有红色室 温磷光发射的纳米粒子. 该纳米粒子分散在水溶液中的粒径约为 $5 \mathrm{~nm}$, 磷光寿命可达 $167 \mu \mathrm{s}$, 同时具有高效的单线态氧产生能力. 这些独特的性质使得该纳米粒子可以在体外和体内有效地杀灭多 重耐药细菌. 本文首次将无金属纯有机磷光纳米粒子用于光动力 抗菌治疗领域, 扩大了无金属有机室温磷光材料的应用范围. 